\title{
Synthesis and characterizations iron oxide carbon nanotubes nanocomposite by laser ablation for anti-microbial applications
}

\author{
Moatasem Al-Salih ${ }^{1 *}$ (D), Syakirah Samsudin ${ }^{1}$ and Siti Suri Arshad ${ }^{2}$
}

\begin{abstract}
Background: Environmental contamination by microbes is a major public health concern. A damp environment is one of the potential sources for microbe proliferation. Smart synthesis nanocatalytic coatings on surfaces, food, and material from different pathogen bacteria can inhibit using the $\mathrm{Fe}_{3} \mathrm{O}_{4} / \mathrm{CNTS}$ as anti-microbial growth can effectively curb this growing threat. In this present work, the anti-microbial efficacy of synthesis of a compound nanoparticlecontaining iron oxide-multi-walled carbon nanotube was combined by laser ablation PLAL and explored the antibacterial action of colloidal solution of $\mathrm{Fe}_{3} \mathrm{O}_{4} / \mathrm{CNTS}$ NPs that was evaluated against bacteria which is classified as gram-negative (Escherichia coli (E. coli), Klebsiella pneumonia (K. pneumonia), and also that is identified as grampositive (Streptococcus pyogenes (S . pyogenes) and Staphylococcus aureus (S. aureus) under visible light irradiation.

Results: Doping of a minute fraction of iron(III) salt ( $0.5 \mathrm{~mol} \%)$ in a volatile solvent (ethanol) was carried out via the sol-gel technique. $\mathrm{Fe}_{3} \mathrm{O}_{4}$ was further calcined at various temperatures (in the range of $500-700{ }^{\circ} \mathrm{C}$ ) to evaluate the thermal stability of the $\mathrm{Fe}_{3} \mathrm{O}_{4}$ nanoporous oxidizer nanoparticles. The physicochemical properties of the samples were characterized through X-ray diffraction (XRD), atomic force microscopy (AFM), attenuated total reflectance Fourier transform infrared spectroscopy (ATR-FTIR), and UV-Visible spectroscopy techniques. XRD results revealed that the nanoparticles framework of $\mathrm{Fe}_{3} \mathrm{O}_{4}$ was maintained well up to $650^{\circ} \mathrm{C}$ by the Fe dopant. UV-Vis results suggested that absorption property of combination $\mathrm{Fe}_{3} \mathrm{O}_{4} / \mathrm{CNTS}$ nanopowder by PLAL was enhanced and the band gap is reduced into $2.0 \mathrm{eV}$.

Conclusions: Density functional theory (DFT) studies emphasize the introduction of $\mathrm{Fe}+$ and Fe2+ ions by replacing other ions in the CNT lattice, therefore creating oxygen vacancies. These further promoted anti-microbial efficiency. A significantly high bacterial inactivation that indicates results was evaluated and that the mean estimations of restraint were determined from triple assessment in every appraisal at $400 \mathrm{ml}$ which represent the best anti-bacterial action against gram-positive and gram-negative microbes.
\end{abstract}

Keywords: Anti-bacteria, $\mathrm{Fe}_{3} \mathrm{O}_{4} / \mathrm{CNTS}$, Nanoparticles, Iron oxide, Multi-walled carbon nanotubes

\section{Background}

In this study, compositing nanoparticles comprising iron oxide inserted with multi-walled carbon nanotubes to create $\mathrm{Fe}_{3} \mathrm{O}_{4} / \mathrm{CNTs}$ nanocomposite were joined with beat laser expulsion of graphite form and $\mathrm{Fe}_{3} \mathrm{O}_{4} / \mathrm{CNTs}$

\footnotetext{
* Correspondence: P20161001028@siswa.upsi.edu.my;

moatasemalsalih@gmail.com

${ }^{1}$ Biology department, Faculty of Science and Mathematics, University

Pendidikan Sultan Idris(UPSI), Tanjung Malim, Malaysia

Full list of author information is available at the end of the article
}

centers around that were inundated in water deionization. The beat laser utilized was Nd:YAG laser of $1046 \mathrm{~nm}$ frequency at altered laser imperativeness masses that reached $5.22-13.07 \mathrm{~J} / \mathrm{cm}^{2}$ and a substitute numeral of $100-400$ beats [1-4].

The visual characterizations of organized impacts were examined while doping the carbon nanoparticles with $\mathrm{Fe}_{3} \mathrm{O}_{4} / \mathrm{CNT}$ s cNPs nanocomposite $[5,6]$ The UltravioletVis assimilation spectra visions demonstrated a redshift as the doping degrees with iron oxide nanoparticles were

\section{Springer Open}

(๑) The Author(s). 2021 Open Access This article is licensed under a Creative Commons Attribution 4.0 International License, which permits use, sharing, adaptation, distribution and reproduction in any medium or format, as long as you give appropriate credit to the original author(s) and the source, provide a link to the Creative Commons licence, and indicate if changes were made. The images or other third party material in this article are included in the article's Creative Commons licence, unless indicated otherwise in a credit line to the material. If material is not included in the article's Creative Commons licence and your intended use is not permitted by statutory regulation or exceeds the permitted use, you will need to obtain permission directly from the copyright holder. To view a copy of this licence, visit http://creativecommons.org/licenses/by/4.0/. 
expanded. While the photoluminescence of carbon nanoparticles doped $\mathrm{Fe}_{3} \mathrm{O}_{4} / \mathrm{CNTs}$, oxide nanoparticles demonstrated a reliable fluorescence outpouring tops in perceptible region at $597 \mathrm{~nm}$ upon excitation at a frequency of $250 \mathrm{~nm}$, yet with lower power, as the doping extent extended; this is an aftereffect of the effect of $\mathrm{Fe}_{3} \mathrm{O}_{4} /$ CNTs nanoparticles in stifling the carbon nanoparticles fluorescence [7-13]. The anti-bacterial development of fused composite nanoparticles was attempted against four particular microorganism minuscule creatures and two gram-negative (Escherichia coli (E.coli), Klebsiella pneumoniae (K. pneumoniae) [8, 9, 14-19].

Likewise, the fundamental technique is fluid substrate methodology in particular gathering of carbon tube nanocomposite masterminded in two laser dynamisms $85 \mathrm{~mJ}$ and $250 \mathrm{~mJ}$ at that point stimulate it with various $\mathrm{Fe}_{3} \mathrm{O}_{4} / \mathrm{CNTs}$, the greatest results were gotten from the $400 \mu \mathrm{g} \mathrm{ml}^{-1}$ of carbon nanotube stimulating with some kind extents of $\mathrm{Fe}_{3} \mathrm{O}_{4} / \mathrm{CNTs}$ nanocomposite [20, 21]. The composite nanopowder that indicated the finest anti-microbial development in the liquid medium system are attempted ceaselessly procedure the incredible scattering technique and reveal that the best centralization of carbon tubes in concentration at $400 \mu \mathrm{g} \mathrm{ml}^{-1}$ which show the influence in anti-microbial actions that are improved and turned out to be better when it doped with $43 \% \mathrm{Fe}_{3} \mathrm{O}_{4}[8,16-20]$.

\section{Aims of the study}

This study aimed to produce and promote a new model of nanocomposite as anti-microbial and anti-germ contamination that made a new profile of anti-resistance nanometers of microorganism, to open new horizons and renaissance for multiple biological applications through low-cost, non-toxic environmentally friendly nanoprocessors. The motivation behind this examination is the brand new model of nanocomposite by changing titanium dioxide for utilizing and obviously saw just as ease and eco-accommodating uncovering the presence of the "wreck" growth of microbe bacteria and how the mix of nanoparticles increment the counter pathogen action. The points of this work are given by some targets:

1. To prepare colloidal iron oxide carbon nanotube composite by beat laser removal procedure in deionized water and orchestrate in this work.

2. To perform laser ablating in iron oxide particles as target in water to synthesize colloidal iron oxide nanoparticles.

3. To identify surface morphology of the stores and materials that have been concentrated by utilizing nuclear power magnifying instruments (AFM). XRD design examination to show the normal grain size and measurements of nanoparticles.

4. To investigate the anti-bacterial movement of $\mathrm{Fe}_{3} \mathrm{O}_{4} /$ CNTs nanotubes against four distinctive microorganism microbes and to investigate the best anti-bacterial action grouping of both alter nanocomposite mixed with $\mathrm{Fe}_{3} \mathrm{O}_{4} /$ CNTs.

\section{Methods \\ Conducting the experiment Combination $\mathrm{Fe}_{3} \mathrm{O}_{4} / \mathrm{CNTS}$ nanopowder}

Nano- $\mathrm{Fe}_{3} \mathrm{O}_{4} / \mathrm{CNTs}$ powder was integrated through a sol-gel strategy utilizing iron(III) salt with an epoxide in a volatile solvent (ethanol) to generate nanoporous oxidizer nanoparticles, isopropanol, and deionized water as beginning materials, prompting the advancement of an airborne based sol-gel strategy for preparing nanoparticles iron-oxide nanoparticles with a high inner surface zone. We have utilized sol-gel responses in the airborne stage utilizing an iron(III) salt with an epoxide in an unstable dissolvable (ethanol) to create nanoporous oxidizer nanoparticles. The porosity of the particles results from the idea of the sol-gel science executed [5-7]. SEM and AFM results show that the vaporized-based science is subjectively like that happening in mass sol - gel union. The oxidizer particles acquired from the air sol-gel test are in the framework demonstrating size range as confirmed by SEM and differential versatility investigation using 3-dimensional AFM [1, 5-7]. Schedules of $\mathrm{Fe}_{3} \mathrm{O}_{4} / \mathrm{CNTs}$ nanoparticles by Nd: YAG laser $(1064 \mathrm{~nm}$, beat span $=9 \mathrm{~ns}$, redundancy recurrence $1 \mathrm{~Hz})$ are working at various energies $(80$ and $200 \mathrm{~mJ})$ for various removal times (10 $\mathrm{min}$ and $20 \mathrm{~min}$ ). Each example was heavy when removal by an advanced weigher to decide LAL iron in refined deionized dish [1, 3, 13-16].

\section{XRD}

Holland Philips X pert X-ray powder diffraction (XRD) diffractometer using monochromatic high-intensity $\mathrm{Cu}$ $\mathrm{K}$, radiation $(\lambda=0.154056 \mathrm{~nm})$, at a scanning speed of $2 " /$ min from $10 "$ to $60 "(2 \theta)$.

\section{AFM}

It is an apparatus which is used to determine or take a picture of the particles, and it used to determine the particle volume in three-dimension $x, y$, and $z$, beside that this apparatus is used to determine the volume distribution of this particles. Angstrom A advanced Inc., USA. Model scanning probe microscope as $3000 \mathrm{~A}$.

\section{ATR-FTIR, UV-Vis}

ATR-FTIR Bruker Model Tensor 27, UV-Visible Spectrophotometer, PG instrument Ltd., double+90Plus. 


\section{Bacterial medium properties}

The bacterial medium was made and well-adjusted by correlated with 0.5 Mc-Farland turbidity commonplace $\left(5 \times 109\right.$ cell in $\left.\mathrm{ml}^{-1}\right)$ tubing test. It was additionally weakened to get a last of $5 \times 107 \mathrm{cell} \mathrm{in} \mathrm{ml}^{-1}$. All microscopic organism strains were cultured in agar media. The media was immunized by the $0.2 \mathrm{ml} / 5 \mathrm{ml}$ with either the microbe's strains, at that point included $0.5 \mathrm{ml}$ of IO-MWCNTs nanoparticles at concentration 50, 100, 200, 400, $600 \mathrm{ml}^{-1}$. The examples were brooded at 37 ${ }^{\circ} \mathrm{C}$. The bacterial development was estimated by an optical thickness that assimilates firmly at $532 \mathrm{~nm}$ frequency by spectrophotometer.

\section{Results}

XRD charts (Fig. 1d) show that the four integrated examples have the most noteworthy diffraction top in the glass-like plane $(\mathrm{A})(2 \theta=29.9202)$ and that the other diffraction tops agree with the translucent periods of (B) (25.9348), (C) $(25,3439)$ and the littlest vertex of (E) (33,
9715). These outcomes have indicated that we can plainly observe that the translucent period of each example is masculine in anatase structure. This outcome corresponds with $[1,2]$. AFM spectra showed (Fig. 1a, b) the moment size conveyance between 60 and $135 \mathrm{~nm}$ for $\mathrm{Fe}_{3} \mathrm{O}_{4} / \mathrm{CNTs}$ and the moment size dispersion between 50 and $150 \mathrm{~nm}$, for $\mathrm{Fe}_{3} \mathrm{O}_{4} / \mathrm{CNTs}$ doped with water orchestrated at $873 \mathrm{k}$. The results show that the $\mathrm{Fe}_{3} \mathrm{O}_{4} / \mathrm{CNTs}$ doped with water has the biggest surface zone, trailed by $\mathrm{Fe}_{3} \mathrm{O}_{4} / \mathrm{CNTs}$ which has a littler surface territory contrasted with the reduction in molecule size $\mathrm{D}$ Avg $=91.24 \mathrm{~nm}$ and the dimer (Fig. 1c) high $Z=0.30$ $\mathrm{nm}$ between the particles is $0.30 \mathrm{~nm}$ (1) discovered goes with [5-7]. The outcomes likewise indicated that an exceptionally noteworthy distinction between the gatherings considered $(P<0.000)$ demonstrated that a high focus in ladies was a lot higher than in the male, which affirms that the presence of the impact is commonly an expansion in the fixation did by introduction to nanoparticles. The outcome likewise demonstrated that
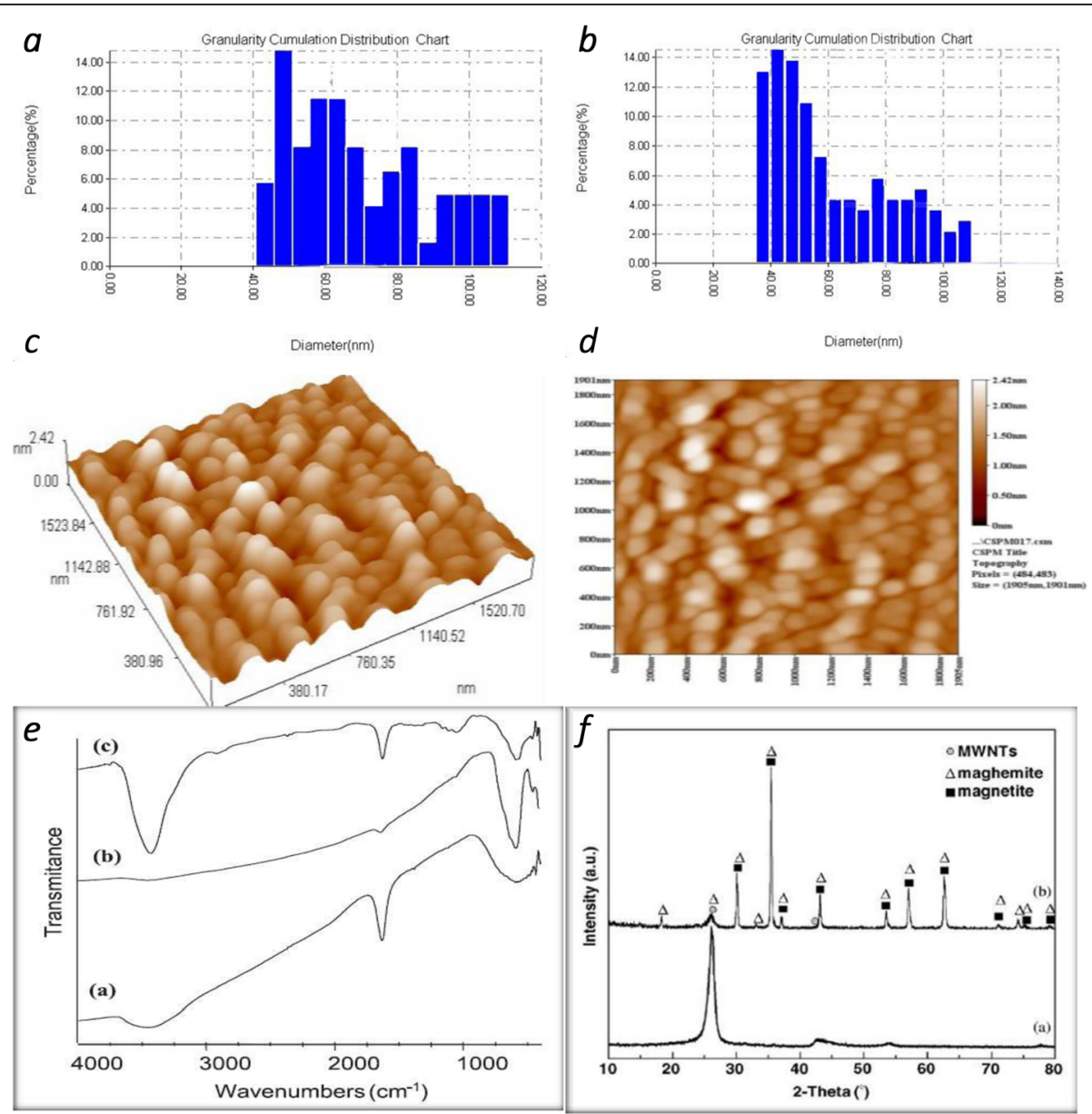

Fig. 1 AFM of $\mathrm{Fe}_{3} \mathrm{O}_{4} / \mathrm{CNTS}$ framework demonstrated $\mathbf{a}$, $\mathbf{b}$ size distribution for catalyst $\mathrm{Fe}_{3} \mathrm{O}_{4} / C N T s$ particle by AFM $\mathbf{c}$ Prepared particles sketched on $X-Y$ axis catalyst, while the $\mathbf{d}$ shows prepared particles sketched on $X-Y-Z$ axis for catalyst. e FTIR spectra of a $C N_{T}, \mathbf{b} \mathrm{Fe}_{3} \mathrm{O}_{4}$, and $\mathbf{c}$ Fe $\mathrm{O}_{4} /$ CNTs composite, $\mathbf{f}$ XRD pattern of $\mathbf{a} \mathrm{Fe}_{3} \mathrm{O}_{4} / \mathrm{CNTS}$ and $\mathbf{b}$ decorated $\mathrm{Fe}_{3} \mathrm{O}_{4} / C N T s$ (maghemite and magnetite) 
distinctions were found between the treatment gathering and the benchmark group; so, this finding concur with [7] and [9], respectively.

\section{Morphological properties}

Figure 2 shows the TEM images of the prepared magnetic nanotube $\mathrm{Fe}_{3} \mathrm{O}_{4} / \mathrm{MWCNTs}$ samples containing elemental iron. The $\mathrm{Fe} 3 \mathrm{O} 4$ nanoparticles appear as spherical nanocrystals that spread on the sidewalls of MWNTs; most tubes were loaded with iron oxide nanoparticles and this can clearly be observed at higher magnification as shown in Fig. $2 b$ that some nanoparticles assembled into nanoclusters. For some individual tubes, the nanoclusters ordered with the iron oxide nanoparticles can completely enwrap the tubes, producing core shell magnetic nanostructures (Fig. 2c). The iron oxide nanoparticles attached strongly and perfectly on the nanotube surface and they look like nodes rising from the nanotube. Figure $2 \mathrm{~d}$ shows TEM images of $\mathrm{MWCNTs} / \mathrm{Fe}_{2} \mathrm{O}_{3}$ that $\mathrm{Fe}_{2} \mathrm{O}_{3}$ was attached to the walls of the MWCNTs representing the high crystallinity of the maghemite nanoparticles [8, 9, 14-19].

\section{Discussion}

The optical properties of prepared collide were investigated before and after doping the carbon nanoparticles with iron oxide nanoparticles. The UV-Vis absorption spectra exhibited a redshift as the doping ratios with iron oxide nanoparticles were increased, while the photoluminescence of carbon nanoparticles doped with iron oxide nanoparticles exhibited a constant fluorescence emission peaks in the visible region at $597 \mathrm{~nm}$ upon excitation at a wavelength of $250 \mathrm{~nm}$, but with lower intensity, as the doping ratio increased; this is because of the effect of iron oxide nanoparticles in quenching the carbon nanoparticles fluorescence this results goes with [1, 3, 13-15].

The structural study of composite carbon nanoparticles doped with different iron oxide nanoparticles has been confirmed using Fourier transform infrared spectrum (FTIR) and X-ray diffraction investigation (XRD). From the FTIR results, it has been successfully found that the $\mathrm{C}-\mathrm{H} \mathrm{C}=\mathrm{C}, \mathrm{C} \equiv \mathrm{C}, \mathrm{C}=\mathrm{O}, \mathrm{C}=\mathrm{O}=\mathrm{C}$, different iron oxide bonds, and $\mathrm{CNT}-\mathrm{IO}$ are confirmed by pulsed laser ablation in the liquid process. XRD patterns that took over a scanning interval from $20^{\circ}$ to $80^{\circ}$ proved the presence of (02) and (100) planes which belong to

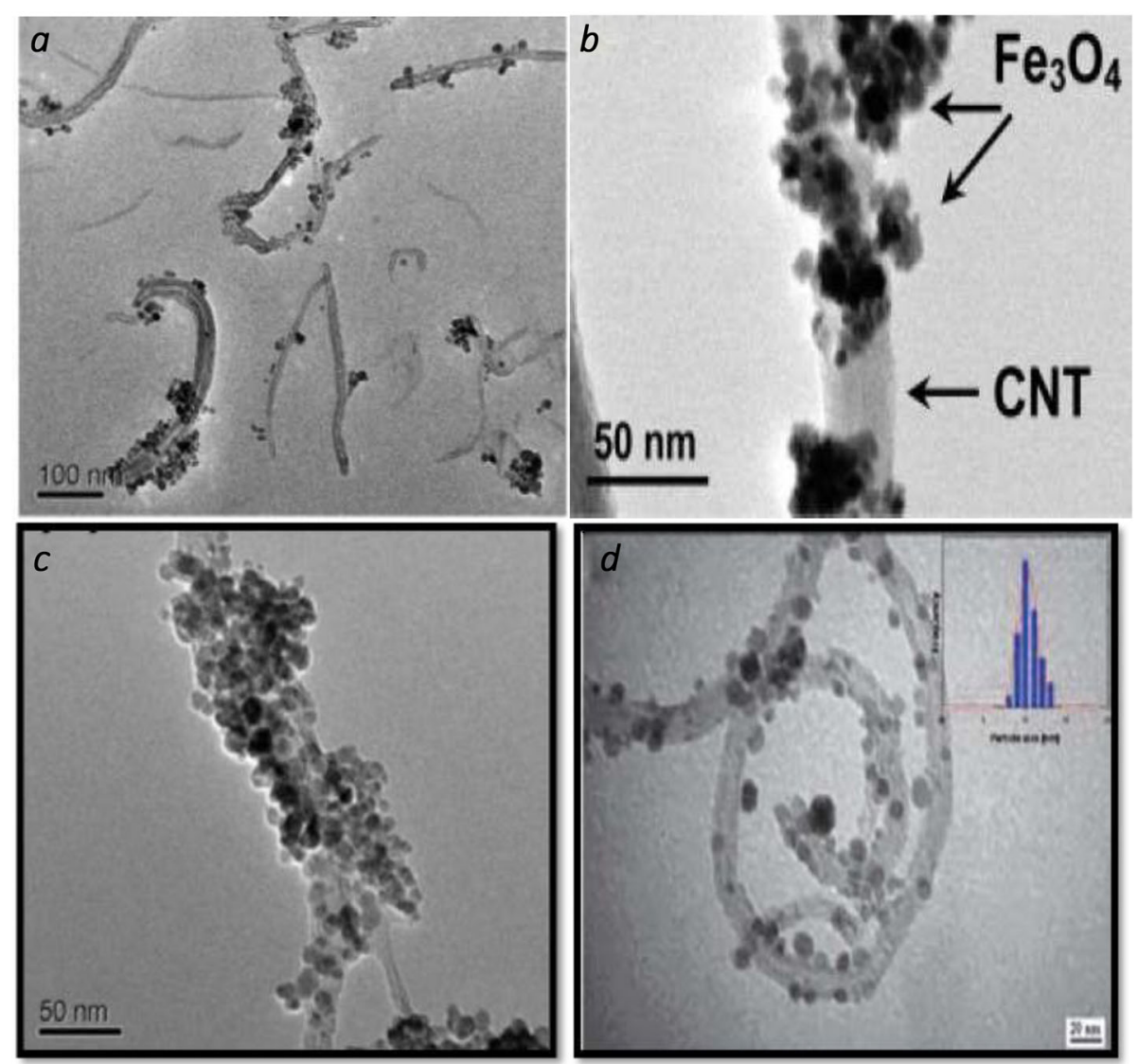

Fig. 2 TEM images of the (a), (b), (c) magnetic nanotube $\mathrm{Fe}_{3} \mathrm{O}_{4} / \mathrm{MWCNTS}$ at two magnification, and (d) TEM images of maghemite $\gamma$--Fe $\mathrm{O}_{3}$ 
graphene layers of multi-walled carbon nanotubes and the honeycomb lattice of the single graphene sheet, also the existent for different planes of iron oxide nanoparticles according to $[1,3,8,9]$.

Morphological properties of composite carbon nanoparticles doped with iron oxide nanoparticles were investigated by transmission electron microscopy(TEM) and energy dispersive spectrum (EDS) are measured; the TEM measurement showed an individual and two straight long multi-walled carbon nanotubes MWCNT with a hollow core adhered. While for composite nanoparticles, the TEM study reveals that there are two types of composite carbon and iron oxides nanoparticles are present; the first type is the iron oxide nanoparticles that attached to the walls of CNT, and the second rare type is carbon-coated iron oxide nanoparticles. The EDS measurements reveal the content of carbon, iron, and oxygen. Readiness strategy utilized prompted getting $\mathrm{Fe}_{3} \mathrm{O}_{4} / \mathrm{CNTs}$ nanoparticles measurements adjusting the band hole and prompted getting a littler band hole (2.0 eV) $\mathrm{Fe}_{3} \mathrm{O}_{4} / \mathrm{CNT}$ s. XRD, AFM gem size, surface morphology, and molecule size and surface geology properties to all examples demonstrated the effective sights of the readied mixes these outcome goes with 14-17, 20-21].

The anti-bacterial movement of combined merged nanocomposite was tried against four diverse microbe microorganisms: two gram-negative (Escherichia coli (E. coli), Klebsiella pneumonia (K. pneumoniae)) and two kinds of gram-positive (Streptococcus pyogenes) and Staphylococcus aureus) with dual strategies; principal strategy is fluid culture cycle that is diverse grouping of nanocomposite arranged in dualistic laser powers that is $80 \mathrm{~mJ}$ and $200 \mathrm{~mJ}$ at that point fixing it with various iron oxide nanopowders. The greatest outcomes were acquired from the $400 \mu \mathrm{g} \mathrm{ml}^{-1}$ of $\mathrm{Fe}_{3} \mathrm{O}_{4} / \mathrm{CNTs}$ nanocomposite drugged with various proportions of nanoparticles. The sterile activity of combination of carbon tube and iron oxide nanocomposite was performed as assay in contradiction of four categories of pathogens; two types of them were the distinction of being gram-negative of bacterial wall as Escherichia coli, Klebsiella pneumoniae, and the other two kinds of them which are distinct being grampositive wall like Streptococcus pyogens and Staphylococcus aureus by well-dispersion techniques. The hatched microscopic organism's media prior to adding the composite of particles appeared in Figs. 3, 5, and 6. The suspension fixations utilized were $400 \mu \mathrm{g} \mathrm{ml}^{-1}$ of just carbon nanotubes utilized as control, and afterward doped with iron oxide NPs of three distinct focuses $\left(100,250,300 \mu \mathrm{g} \mathrm{ml}{ }^{-1}\right)$, which spoke to by doping proportions $(20,38,43 \%)$ separately, gotten by laser removal of carbon and iron focuses in deionized water at a laser energy thickness of $5.2 \mathrm{~J} / \mathrm{cm}^{2}$. Composite nanoparticles, which have demonstrated the best anti-bacterial activity in a fluid medium technique, are continually tried in a well-dissipating technique procedure and find that the best combinations of $400 \mu \mathrm{g} / \mathrm{ml}$ carbon nanotubes, which show the best anti-bacterial activity, are improved and end up being better when doped with $43 \%$ nanoparticles that indicate the outcome correspondence with [14-19].

As shown in Fig. 4, determining the inhibiting zone IZ region by capacity of that nobbling the iron oxide-MWCN Ts nanocomposite container improved the anti-growth of bacteria activity interaction with pathogen culture distinguishing gram-negative, and this activity increased clearly with the increase of the IO NPs concentrations. Figure 3 exhibits the histograms of the anti-bacterial activity against two gram-negative $E$. coli and $K$. pneumoniae pathogens which were induced by carbon nanotubes at $400 \mu \mathrm{g} \mathrm{ml}{ }^{-1}$ concentration and composite multi-walled carbon nanotubes doped with iron oxide NPs at three different concentrations ratios $(20,38,42 \%)$. Figure 5 shows the inhibition zone (IZ) image of carbon nanotubes of 400 $\mu \mathrm{g} \mathrm{ml}^{-1}$ which represented as control without adding iron

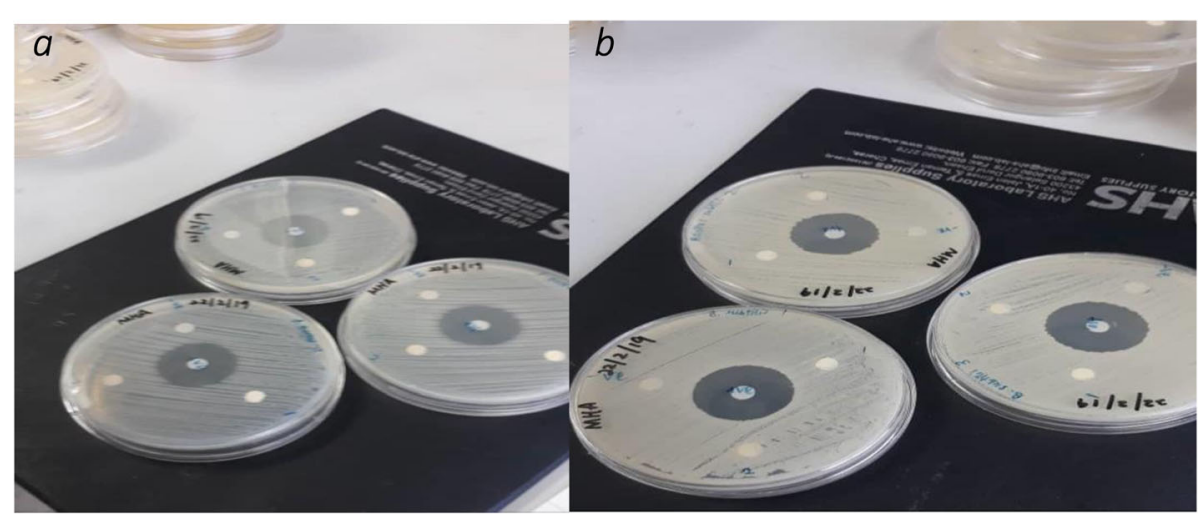

Fig. 3 This figure showed the difference between effective nanoparticles in bacteria growth in media these particles which experimenting configuration in Laser ablation in liquefied setups where a focused beam irradiated; bacterial target placed in pure melted a colloidal solution of nanoparticles. a) refer to replicate in three madia in E. coli. b) K. pneumonia $n=3$ 


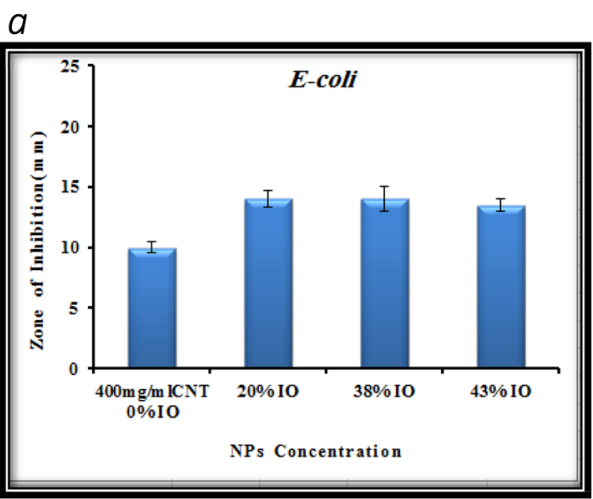

\section{$b$}

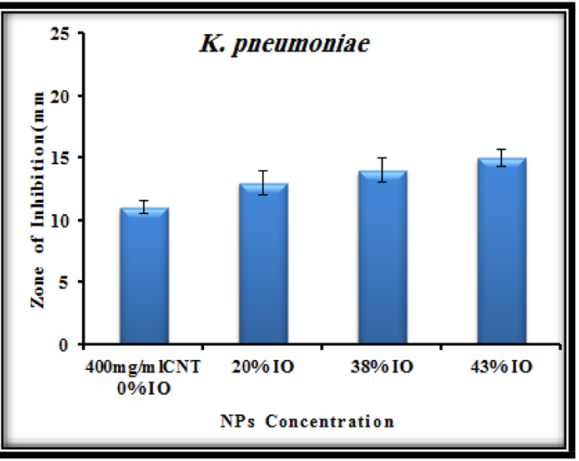

Fig. 4 Histograms of Anti-microbial growth activity stimulated by IO-MWCNTs. Composite against two types of bacteria gram negative: (a) E. coli, (b) K. pneumonia

oxide nanoparticles, and composite carbon and iron oxide NPs in three concentrations that maintained above according to $[8,9,20,21]$.

Figures 5 and 6 demonstrate the histograms and inhibition zone (IZ) image, respectively, of the anti-bacterial growth in media against gram-positive Streptococcus pyogens (S. pyogenes) and Staphylococcus aureus (S. aureus) pathogens which were induced by carbon nanotubes at $400 \mu \mathrm{g} \mathrm{ml}^{-1}$ concentration and composite carbon nanotubes doped with iron oxide NPs at three different concentrations ratios $(20,38,42 \%)$ that goes with $[4,8$, $9,14,15]$.

At last, utilizing the $\mathrm{Fe}_{3} \mathrm{O}_{4} / \mathrm{CNTs}$ as anti-microbial was tested against four different pathogen bacteria two gramnegative (Escherichia coli (E. coli), Klebsiella pneumoniae (K. pneumoniae)), and two gram-positive (Streptococcus pyogenes (S. pyogenes) and Staphylococcus aureus (S. aureus)) by two methods: the first method is a liquid medium method in which different concentrations of multi-walled carbon nanoparticles were prepared in two laser energies $(80 \mathrm{~mJ}$ and $200 \mathrm{~mJ}$ ) then doping them with different iron oxide nanoparticles; the best results were obtained from the 400 $\mu \mathrm{g} \mathrm{ml}^{-1}$ multi-walled wall carbon nanoparticles doped with different ratios of iron oxide nanoparticles. The composite nanoparticles that exhibited the best anti-bacterial activity in the liquid medium method are tested by the second method, the good diffusion method, and reveals that the best concentration of multi-walled carbon nanotubes $\left(400 \mu \mathrm{g} \mathrm{m}{ }^{-1}\right)$ that exhibit the best anti-oval activity are enhanced and become better when it doped with $43 \%$ iron oxide nanoparticles.
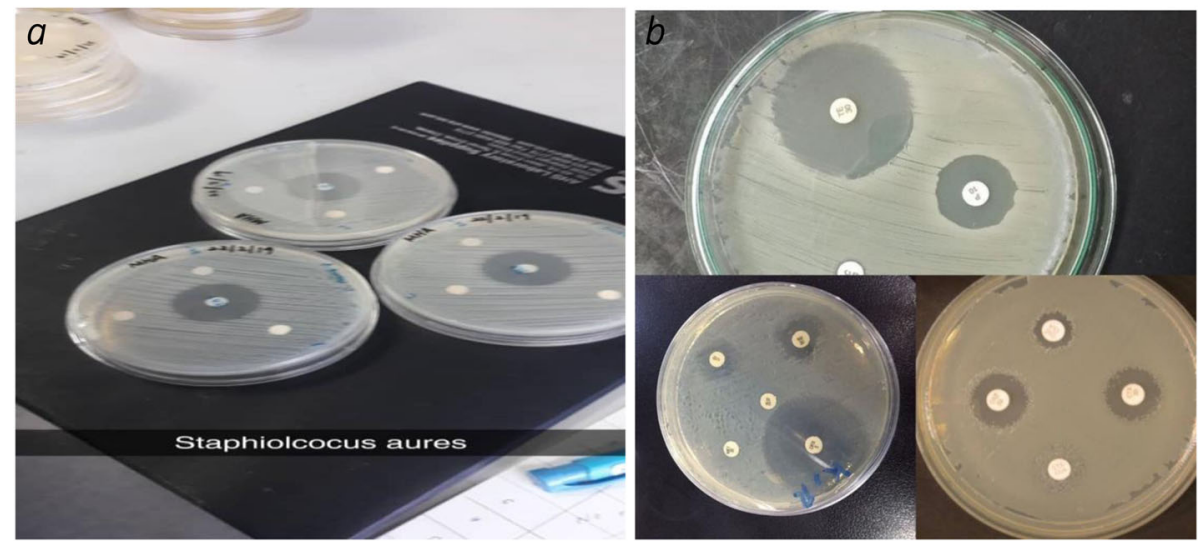

Fig. 5 demonstrate the histograms and inhibition zone (IZ) image respectively of the anti-bacterial growth in media (a) against gram-positive Streptococcus pyogens (S. pyogenes) replicate three media $n=3$. (b) in Staphylococcus aureus (S. aureus) pathogens, which induced by carbon nanotubes at $400 \mathrm{\mu g} \mathrm{mL}^{-1}$ concentration and composite carbon nanotubes doped with Iron Oxide NPs at three different concentrations ratios $(20,38,42 \%)$ in three media 
$a$

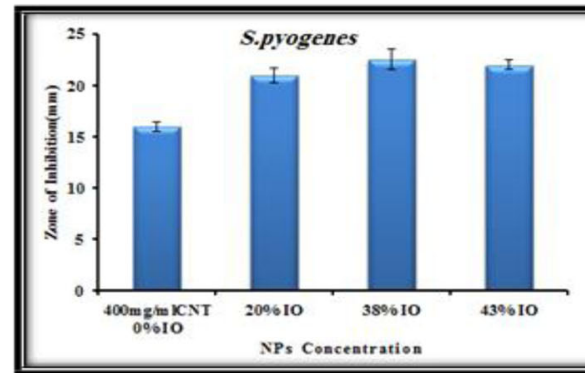

$b$

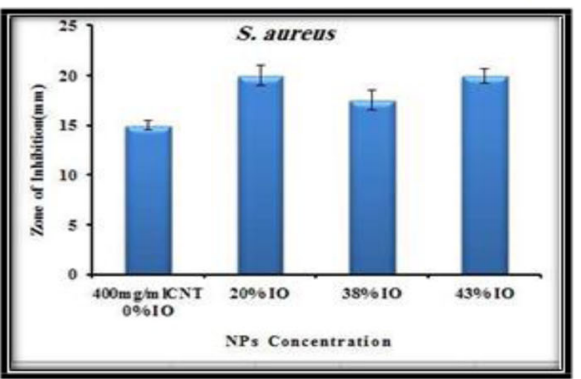

Fig. 6 Images and histograms of Anti-bacterial growth reduced by IO-MWCNTs and composite that's dubbing IO-MWCNTs NPs against two gram-positive (a) S. pyogenes and (b) Staphylococcus aureus (S. aureus)

\section{Conclusions}

As a result of this work, the end could be summed up as follows:

1. For optical properties, the absorbance of both carbon nanotubes and iron.

2. Oxide nanoparticles were expanded as laser energy and removal time were expanded as well, while the photoluminescence (PL) of carbon nanotubes diminished with expanding the doping proportions of iron oxide NPs.

3. Carbon NPs were incorporated in two structures (nanotubes and graphene sheet), and the iron oxide nanoparticles with round shapes were totaled around the carbon nanotubes; this accumulation expanded as laser removal time emerges. The second type of orchestrated composite NPs was seen as iron oxide NPs encompassed with graphene sheet.

4. The best anti-bacterial action against gram-positive and gram-negative microbes was for the fixations $400 \mu \mathrm{g} / \mathrm{ml}$ doped with various proportions of iron oxide nanoparticles more than for $200 \mu \mathrm{g} / \mathrm{ml}$ doped additionally with various iron oxide proportions because of the impact of arranged nanoparticles size.

5. The anti-bacterial movement for the composite carbon nanotubes doped with iron oxide nanoparticles was higher against gram-positive Streptococcus pyogenes (S. pyogenes) and Staphylococcus aureus (S. aureus) than for gram-negative microbes $E$. coli and K. pneumonia.

\section{Abbreviations}

NPs: Nanoparticles; $\mathrm{Fe}_{3} \mathrm{O}_{4} / \mathrm{CNTS}$ : Iron oxide/Carbon Nanotube; MWCN Ts: Multi-walled carbon nanotubes; E. coli: Escherichia coli; K. pneumonia: Klebsiella pneumoniae; S. pyogenes: Streptococcus pyogenes; S. aureus: Staphylococcus aureus; ATR-FTIR: Attenuated total reflectance Fouriertransformed infrared spectroscopy; XRD: X-ray diffraction; TEM: Transmission electron microscopy; AFM: Atomic force microscopy

\section{Acknowledgements}

The authors thank and gratefully appreciate the Faculty of Science and Mathematics for acknowledgement GPU Grant 2016-0223-101-41 and their facilities to accomplish this research.

\section{Authors' contributions}

MA-S conceived of the presented idea with conceived experimental procedure in the technician side also interested in offering the logistics supporting developed the theory and performed the computations. As well as focuses work on nanoparticles materials and investigation of characterization properties of the material framework. In methodology and laboratory part he is verified the analytical methods especially; in to investigate concerning modifying energy power of material according to verify each of following parameters: Fourier Transform Infrared (FTIR) Measurements, X-Ray Diffraction Pattern Measurement, Morphological Measurements, Transmission Electron Microscope (TEM), Energy Dispersive Spectrum (EDS). Investigated the physical and chemical properties of carbon nanotubes doped with iron oxide and supervised the findings of this work focus on microbial models, he was discussed the results and contributed to the final conceptual framework. He was writing the manuscript with support by the authors contributed to the interpretation of the results. He took the lead in writing the manuscript. All authors provided critical feedback and helped shape the research, analysis, and manuscript. He and Syakira took the re-evaluation of results. He and all authors discussed the results and commented on the manuscript after the end of the study wrote by them. SS was conceived of the presented idea and put the outline of the study according to the time chart as well as subdivided the study according to the major and minor objective to make the streamlining of work according to the numeric of objectives that was set for it, in chronological order, after that she was conceived of the presented physiological and biochemistry influencer in this study. She with Dr. Moatasem verified the analytical methods. An encouraged Moatasem to investigate the physical and chemical properties of carbon nanotubes doped with iron oxide and supervised the findings of this work focus on microbial models. Also she with authors discussed the results and contributed to the final conceptual framework. She was taking the re-evaluation of results. SSA She was and all authors author contribution problem statements in the study. Her main concern was the delicate daily follow-up of the practical and technical side, conceived experimental procedure in the technician side also interested in offering the logistics supporting developed the theory and performed the computations. At last, she was contributed re-recommendation to the design and implementation of the research, to the analysis of the results, and to the writing of the manuscript in final form. All authors read and approved the final manuscript.

Funding

GPU Grant 2016-0223-101-41 awards from Faculty of Science and Mathematics, UPSI University.

Availability of data and materials

We have taken due care that the scientific knowledge, historical data, evidential artifacts, figures, and all other statements contained in the article 
conform to true facts and authentic formulae and will not, if followed precisely, be detrimental to the user.

We permit the adaptation, preparation of derivative works, oral presentation, or distribution, along with the commercial application of the work. Copyright is given at the Org level and so Journal of Genetic Engineering and Biotechnology can determine the journal in which the paper is to be published or change the journal at any point in time in which the paper is to be published.

\section{Declarations}

\section{Ethics approval and consent to participate}

The article submitted is an original work and has neither been published in any other peer-reviewed journal nor is under consideration for publication by any other journal. More so, the article does not contravene any existing copyright or any other third party rights.

We are the sole authors of the article and maintain the authority to enter into this agreement and the grant of rights to Journal of Genetic Engineering and Biotechnology, jgeb.springeropen.com, does not infringe any clause of this agreement.

\section{Consent for publication}

The article contains no such material that may be unlawful, defamatory, or which would, if published, in any way whatsoever, violate the terms and conditions as laid down in the agreement.

\section{Competing interests}

The authors declare that they have no competing interests.

\section{Author details}

${ }^{1}$ Biology department, Faculty of Science and Mathematics, University Pendidikan Sultan Idris(UPSI), Tanjung Malim, Malaysia. ${ }^{2}$ Faculty of Veterinary Medicine, University Putra, Seri Kembangan, Malaysia.

\section{Received: 26 November 2020 Accepted: 5 April 2021}

Published online: 18 May 2021

\section{References}

1. Thongpoola V, Asanithia P, Limsuwana P (2012) Synthesis of carbon particles using laser ablation in ethanol. Proc Eng 32:1054-1060. https://doi. org/10.1016/j.proeng.2012.02.054

2. Reyes-Contreras D, Camacho-López M, Camacho-López MA, CamachoLópez S, Rodríguez-Beltrán Rl, Mayorga-Rojas M (2015) Influence of the per pulse laser fluence on the optical properties of carbon nanoparticles synthesized by laser ablation of solids in liquids. Opt Laser Technol 74:4852. https://doi.org/10.1016/j.optlastec.2015.05.010

3. Bai Y, Park IS, Lee SJ, Bae TS, Watari F, Uo M, Lee MH (2011) Aqueous dispersion of surfactant-modified multiwalled carbon nanotubes and their application as an antibacterial agent. Carbon 49(11):3663-3671. https://doi. org/10.1016/j.carbon.2011.05.002

4. Cabeen MT, Jacobs-Wagner C (2005) Bacterial cell shape. Nat Rev Microbiol 3(8):601-610. https://doi.org/10.1038/nrmicro1205

5. Wang T, Zhu YC, Sun ZX, Wu LG (2015) Preparation of weak light driven $\mathrm{TiO} 2$ multi composite photocatalysts via adsorption phase synthesis. Huan Jing Ke Xue 36(2):559-567 PMID: 26031083

6. Azri N, Bakar WA, Ali R (2016) Optimization of photocatalytic degradation of polybrominated diphenyl ether on trimetallic oxide $\mathrm{Cu} / \mathrm{Ni} / \mathrm{TiO} 2 / \mathrm{PVC}$ catalyst using response surface methodology method. J Taiwan Inst Chem Eng 62: 283-296. https://doi.org/10.1016/j.jtice.2016.01.020

7. López-Muñoz D, Ochoa-Zapater MA, Torreblanca A, Garcerá MD (2019) Evaluation of the effects of titanium dioxide and aluminium oxide nanoparticles through tarsal contact exposure in the model insect Oncopeltus fasciatus. Sci Total Environ 666:759-765. https://doi.org/10.1016/ j.scitotenv.2019.02.218

8. Fazio E, Santoro M, Lentini G, Franco D, Guglielmino SP, Neri F (2016) Iron oxide nanoparticles prepared by laser ablation: synthesis, structural properties and antimicrobial activity. Colloids Surf A Physicochemical Eng Aspects 490:98-103. https://doi.org/10.1016/j.colsurfa.2015.11.034

9. Situ SF, Samia AC (2014) Highly efficient antibacterial iron oxide@ carbon nanochains from wustite precursor nanoparticles. ACS Appl Mater Interfaces 6(22):20154-20163. https://doi.org/10.1021/am505744m
10. Mostafa AM, Mwafy EA, Awwad NS, Ibrahium HA (2021) Linear and nonlinear optical studies of $\mathrm{Ag} / \mathrm{Zn} / \mathrm{ZnO}$ nanocomposite thin film prepared by pulsed laser deposition technique. Radiat Phys Chem 179:109233. https://doi.org/10.1016/j.radphyschem.2020.109233

11. Mwafy EA, Mostafa AM (2021) Efficient removal of Cu (II) by SnO2/MWCNTs nanocomposite prepared by pulsed laser ablation in liquid media. NanoStruct Nano-Objects 24:100591. https://doi.org/10.1016/j.nanoso.2020.100591

12. Mostafa AM (2021) Preparation and study of nonlinear response of embedding ZnO nanoparticles in PVA thin film by pulsed laser ablation. J Mol Struct 1223:129007. https://doi.org/10.1016/j.molstruc.2020.129007

13. Mwafy EA, Mostafa AM (2020) MWCNTs/SnO2 decorated cellulose nanofiber adsorbent for the removal of Cu (II) from waste water. Radiat Phys Chem: 109172. https://doi.org/10.1016/j.radphyschem.2020.109172

14. Mostafa AM, Mwafy EA (2020) The effect of laser fluence for enhancing the antibacterial activity of $\mathrm{NiO}$ nanoparticles by pulsed laser ablation in liquid media. Environ Nanotechnol Monit Manage 14:100382. https://doi.org/10.1 016/j.enmm.2020.100382

15. Mostafa AM, Mwafy EA (2020) Effect of dual-beam laser radiation for synthetic SnO2/Au nanoalloy for antibacterial activity. J Mol Struct 1222: 128913. https://doi.org/10.1016/j.molstruc.2020.128913

16. Mostafa AM, Mwafy EA, Hasanin MS (2020) One-pot synthesis of nanostructured CdS, CuS, and SnS by pulsed laser ablation in liquid environment and their antimicrobial activity. Opt Laser Technol 121:105824. https://doi.org/10.1016/j.optlastec.2019.105824

17. Mostafa AM, Mwafy EA (2020) Synthesis of ZnO and Au@ ZnO core/shell nano-catalysts by pulsed laser ablation in different liquid media. J Mater Res Technol 9:3241-3248. https://doi.org/10.1016/j.jmrt.2020.01.071

18. Mwafy EA, Hasanin MS, Mostafa AM (2019) Cadmium oxide/ TEMPOOxidized cellulose nanocomposites produced by pulsed laser ablation in liquid environment: synthesis, characterization, and antimicrobial activity. Opt Laser Technol 120:105744. https://doi.org/10.1016/j.optlastec.2019.1 05744

19. El-Saied H, Mostafa AM, Hasanin MS, Mwafy EA, Mohammed AA (2020) Synthesis of antimicrobial cellulosic derivative and its catalytic activity. J King Saud Univ Sci 32(1):436-442. https://doi.org/10.1016/j.jksus.2018.06.007

20. ElFaham M, Okil M, Mostafa AM (2020) Effects of post-laser irradiation on the optical and structure properties of $\mathrm{Al} 2 \mathrm{O} 3$ nanoparticles produced by laser ablation. J Appl Phys 128:153104. https://doi.org/10.1063/5.0022554

21. Mwafy EA, Mostafa AM (2019) Multi walled carbon nanotube decorated cadmium oxide nanoparticles via pulsed laser ablation in liquid media. Opt Laser Technol 111:249-254. https://doi.org/10.1016/j.optlastec.2018.09.055

\section{Publisher's Note}

Springer Nature remains neutral with regard to jurisdictional claims in published maps and institutional affiliations.

\section{Submit your manuscript to a SpringerOpen ${ }^{\circ}$ journal and benefit from:}

- Convenient online submission

- Rigorous peer review

- Open access: articles freely available online

- High visibility within the field

- Retaining the copyright to your article

Submit your next manuscript at $>$ springeropen.com 